\title{
Measuring the body composition of elderly subjects: a comparison of methods
}

\author{
BY J. J. REILLY, L. A. MURRAY, J. WILSON AND J. V. G. A. DURNIN \\ University of Glasgow Department of Human Nutrition, Yorkhill Hospitals, Glasgow G3 8SJ
}

(Received 23 August 1993 -Revised 19 November 1993 - Accepted 22 November 1993)

\begin{abstract}
There is a paucity of data on differences between methods for the assessment of body composition in elderly subjects. Studies on younger adults suggest that such differences are of some practical significance at the individual level. In the present study the following methods of estimating percentage body fatness (BF\%) were compared in healthy elderly men and women (mean age 70 (SD 6) years: densitometry; skinfold thickness; total body water; bioelectrical impedance (BIA) using an age-specific predictive equation and the manufacturers' equation; body mass index (BMI). Though BF\% estimates from the various methods tended to be highly correlated with those from densitometry and with each other, differences between methods at the individual level were marked. In particular, the age-specific equations based on BMI and BIA systematically overestimated BF \% relative to the other methods. Biases between BF \% estimates derived from densitometry, skinfolds, BIA (manufacturers' equation) and total body water were less marked, indicating little evidence of systematic differences between these methods in elderly subjects. Individual differences between methods were slightly greater than those reported in some studies of younger adults, but this may be of little practical significance, and may be considered inevitable in view of variability between and within subjects in the extent to which the underlying assumptions of these two-component methods are met in elderly subjects.
\end{abstract}

Fat-free mass: Ageing: Methodology

The need for improved information on the methodology for assessment of body composition of elderly subjects ( $>65$ years) has been identified by a number of investigators (e.g. Durnin, 1983; Kuczmarski, 1989; Baumgartner et al. 1991). Ageing is characterized by: reduction in fat-free mass (FFM; Forbes, 1987), primarily via loss of muscle mass; loss of bone mineral in women (Mazess, 1982); redistribution of body fat leading to increased deposition of body fat in 'internal' fat depots as opposed to subcutaneous depots (Durnin \& Womersley, 1974). Though the general pattern of change in body composition in old age is clear, it is also clear that the rate, timing and extent of the changes varies between subjects and between the sexes (Deurenberg et al. 1989; Heymsfield et al. 1989). Both the changes and the degree of variability in the changes present particular problems for the assessment of body composition by two-component methods in elderly subjects since the underlying assumptions upon which the various techniques are based may be invalid. Concern has been expressed in relation to the use of total body $\mathrm{K}$ which is flawed by loss of muscle in old age (Cohn et al. 1980). Estimates using total body water (TBW) may also be flawed if the water content of FFM alters systematically with old age, but there is little evidence of a systematic change of this kind (Schoeller, 1989). Bioelectrical impedance (BIA) has practical utility in elderly subjects but use of age-specific predictive equations is likely to be necessary, since application of equations derived from younger populations in elderly subjects may lead to systematic 
overestimation of FFM (Deurenberg et al. 1990). The prediction of body density by skinfold thickness is of value in elderly subjects, but concern has been expressed in relation to overestimation of body density particularly in women (Reilly et al. 1993). An alternative anthropometric approach based on prediction of body fatness in individuals from body mass index (BMI) has been shown to have some promise (Deurenberg et al. 1991) in elderly subjects. Finally, in most studies which have adopted two-component methods the reference method adopted is body density, but there are particular problems with the use of densitometry as a reference method in the elderly because of variability in the density of FFM such that the assumption of a constant density of $1.100 \mathrm{~kg} / \mathrm{m}^{3}$ may be invalid (Deurenberg et al. 1989).

In recent years advances in technology have permitted the construction of models of body composition which define the body in terms of more than two components. These models are of particular value in population groups where the two-component model is limited by variability in the composition of FFM, notably in children and the elderly (e.g. Svendsen et al. 1991; Friedl et al. 1992). However, further development of this approach is necessary and cross-validation of any equations arising from it is awaited. For many investigators two-component methodology will remains the only option for the foreseeable future because of practical constraints. Moreover, in many 'field', community, and clinical settings the techniques derived from the two-component approach (e.g. skinfold thickness and BIA) are the only appropriate means of body composition assessment. Our approach here has been to characterize differences between two-component methods currently available for use in elderly subjects. Detailed characterization of differences between methods at the level of the individual is virtually absent in elderly subjects. These differences are quite marked in younger groups of adults (McNeill et al. 1991; Fuller et al. 1992) and might be even more marked in elderly subjects because of variability in the rate, extent or timing of the changes in body composition outlined above.

The aims of the present study were as follows: (1) To compare methods for the assessment of body composition in healthy elderly subjects by application of several methods on the same subject; (2) to test the validity of predictive equations based on BIA and BMI, developed in other elderly populations, for use in the selected population recruited in this study.

\section{SUBJECTS AND METHODS}

\section{Subjects}

The participants were sixty elderly subjects (thirty-three females, twenty-seven males). All were in good health, living in the community, and were recruited by newspaper advertisement. All subjects provided a brief medical history and were free of disease which might have been relevant to consideration of body composition (diagnosis of osteoporosis, renal or hepatic disease, malignancy, cardiovascular disease). The research was approved by the Glasgow West Ethics Committee, and all subjects provided informed consent to the procedures described here. Characteristics of subjects are given in Tables 1 and 2. Subjects were not selected on the basis that they were to comprise a representative sample of the elderly living in the community, but comparison of the males and females separately with appropriate reference values for the UK (Burr \& Phillips, 1984) revealed no significant differences between the sample selected and reference data for community elderly subjects with respect to age, body weight, or body composition estimated from skinfold thickness $(t$ test, $P>0.05)$.

Of the sixty subjects selected, twenty-five were unable or unwilling to participate in the underwater weighing procedure for determination of body density. Subjects in whom density was not measured did not have TBW determined. The remaining thirty-five subjects 
Table 1. Characteristics of male subjects (n 27) participating in the study

\begin{tabular}{|c|c|c|c|c|c|}
\hline $\begin{array}{l}\text { Subject } \\
\text { no. }\end{array}$ & $\begin{array}{c}\text { Age } \\
\text { (years) }\end{array}$ & $\begin{array}{l}\text { Weight } \\
\text { (kg) }\end{array}$ & $\begin{array}{l}\text { Height } \\
\text { (m) }\end{array}$ & $\begin{array}{c}\mathrm{BMI} \\
\left(\mathrm{kg} / \mathrm{m}^{2}\right)\end{array}$ & $\begin{array}{l}\text { Participation in } \\
\text { complete study* }\end{array}$ \\
\hline 02 & 66 & 87.0 & 1.82 & $26 \cdot 4$ & $\mathrm{Y}$ \\
\hline 03 & 71 & $85 \cdot 0$ & 1.79 & $26 \cdot 5$ & $\mathrm{Y}$ \\
\hline 04 & 67 & 67.0 & 1.65 & $24 \cdot 7$ & Y \\
\hline 06 & 75 & $83 \cdot 0$ & 1.67 & $29 \cdot 6$ & $\mathbf{N}$ \\
\hline 08 & 67 & 88.5 & 1.75 & $28 \cdot 9$ & $\mathbf{Y}$ \\
\hline 09 & 64 & 90.0 & 1.66 & $32 \cdot 5$ & $Y$ \\
\hline 20 & 72 & 54.5 & 1.61 & $21 \cdot 0$ & $Y$ \\
\hline 22 & 73 & $59 \cdot 5$ & 1.65 & $23 \cdot 1$ & $\mathrm{Y}$ \\
\hline 33 & 66 & $71 \cdot 1$ & 1.70 & $24 \cdot 6$ & $\mathrm{Y}$ \\
\hline 35 & 65 & 85.0 & 1.76 & $27 \cdot 4$ & $\mathbf{N}$ \\
\hline 37 & 65 & $70 \cdot 0$ & 1.81 & $21 \cdot 3$ & $\mathbf{Y}$ \\
\hline 38 & 68 & $79 \cdot 5$ & 1.85 & $23 \cdot 2$ & $Y$ \\
\hline 39 & 70 & $86 \cdot 5$ & 1.78 & $27 \cdot 3$ & $Y$ \\
\hline 43 & 66 & $64 \cdot 0$ & 1.63 & $24 \cdot 2$ & $\mathrm{Y}$ \\
\hline 46 & 69 & $79 \cdot 0$ & 1.78 & $24 \cdot 9$ & $\mathrm{Y}$ \\
\hline 50 & 66 & 95.8 & 1.73 & 31.9 & $\mathbf{N}$ \\
\hline 51 & 75 & 67.0 & 1.78 & $21 \cdot 3$ & $\mathrm{Y}$ \\
\hline 53 & 71 & $61 \cdot 0$ & 1.65 & $22 \cdot 5$ & $\mathrm{Y}$ \\
\hline 55 & 84 & $60 \cdot 8$ & 1.59 & $24 \cdot 0$ & $\mathrm{~N}$ \\
\hline 67 & 70 & $93 \cdot 5$ & 1.85 & $27 \cdot 5$ & $\mathrm{Y}$ \\
\hline 69 & 93 & $51 \cdot 2$ & 1.61 & $19 \cdot 8$ & $\mathbf{N}$ \\
\hline 70 & 66 & $64 \cdot 5$ & 1.63 & $24 \cdot 3$ & $\mathbf{Y}$ \\
\hline 75 & 65 & $71 \cdot 0$ & 1.75 & $23 \cdot 1$ & $\mathrm{Y}$ \\
\hline 79 & 65 & 93.8 & 1.79 & $29 \cdot 2$ & $Y$ \\
\hline 87 & 68 & $74 \cdot 8$ & 1.68 & $26 \cdot 6$ & $Y$ \\
\hline 88 & 71 & $77 \cdot 5$ & 1.71 & $26 \cdot 5$ & $\mathrm{~N}$ \\
\hline 89 & 66 & $80-0$ & 1.82 & $24 \cdot 2$ & $\mathbf{N}$ \\
\hline Mean & 70 & $75 \cdot 6$ & 1.72 & $25 \cdot 4$ & \\
\hline SD & 6 & $12 \cdot 7$ & 0.08 & 3.2 & \\
\hline
\end{tabular}

BMI, body mass index; $Y$, yes; $N$, no.

* Subjects who did not participate in the complete study were, by definition, not included in the measurements of total body water and underwater weighing.

participated in all procedures (including measurement of TBW) described below and therefore the sample size for all methodological comparisons was thirty-five (nineteen males, sixteen females), but for comparison of methods other than densitometry and TBW sample size was sixty.

\section{Anthropometry}

Subjects visited the laboratory in the early morning after an overnight fast and were weighed to $0 \cdot 1 \mathrm{~kg}$ in light indoor clothing. This was corrected to nude weight. Height was measured to $2 \mathrm{~mm}$. The procedures described below were then performed on the same day.

\section{Skinfold thickness (SFT)}

Skinfolds were measured at four standard sites: biceps, triceps, suprailiac and sub-scapular, as previously described (Durnin \& Womersley, 1974). Body density was predicted in all subjects using the appropriate equation from Durnin \& Womersley (1974). All measurements were carried out by the same trained observer. The estimate of density 
Table 2. Characteristics of female subjects (n 33) participating in the study

\begin{tabular}{|c|c|c|c|c|c|}
\hline $\begin{array}{c}\text { Subject } \\
\text { no. }\end{array}$ & $\begin{array}{c}\text { Age } \\
\text { (years) }\end{array}$ & $\begin{array}{l}\text { Weight } \\
(\mathrm{kg})\end{array}$ & $\begin{array}{l}\text { Height } \\
\text { (m) }\end{array}$ & $\underset{\left(\mathrm{kg} / \mathrm{m}^{2}\right)}{\mathrm{BMI}}$ & $\begin{array}{l}\text { Participation in } \\
\text { complete study* }\end{array}$ \\
\hline 01 & 69 & 68.5 & 1.54 & $29 \cdot 0$ & $\mathrm{Y}$ \\
\hline 07 & 72 & $70 \cdot 1$ & 1.65 & $25 \cdot 9$ & $\mathbf{Y}$ \\
\hline 12 & 75 & 58.5 & 1.59 & $23 \cdot 1$ & $\mathbf{Y}$ \\
\hline 15 & 66 & $76 \cdot 5$ & 1.58 & 30.8 & $\mathrm{Y}$ \\
\hline 18 & 66 & 59.5 & 1.56 & 24.5 & $\mathrm{Y}$ \\
\hline 19 & 66 & 67.5 & 1.62 & 25.8 & $\mathrm{Y}$ \\
\hline 21 & 67 & 47.5 & 1.60 & 18.7 & $\mathrm{Y}$ \\
\hline 23 & 71 & 99.5 & 1.66 & 36.0 & $\mathbf{N}$ \\
\hline 25 & 79 & $71 \cdot 5$ & 1.62 & 27.2 & $\mathrm{~N}$ \\
\hline 26 & 68 & $52 \cdot 0$ & 1.47 & 24.0 & $\mathrm{Y}$ \\
\hline 27 & 72 & 71.0 & 1.56 & $29 \cdot 1$ & $\mathbf{N}$ \\
\hline 31 & 70 & 70.0 & 1.57 & 25.4 & $\mathbf{N}$ \\
\hline 32 & 66 & 62.5 & 1.57 & $25 \cdot 3$ & $\mathbf{N}$ \\
\hline 40 & 68 & $56 \cdot 5$ & 1.57 & $23 \cdot 0$ & $\mathrm{Y}$ \\
\hline 42 & 78 & $49 \cdot 3$ & 1.54 & 20.7 & $\mathrm{Y}$ \\
\hline 44 & 66 & 63.0 & 1.64 & $23 \cdot 4$ & $\mathrm{Y}$ \\
\hline 45 & 66 & $70 \cdot 0$ & 1.52 & $30 \cdot 1$ & $\mathrm{~N}$ \\
\hline 47 & 76 & $61 \cdot 2$ & 1.56 & $25 \cdot 1$ & $\mathrm{Y}$ \\
\hline 48 & 77 & $70 \cdot 3$ & 1.65 & $26 \cdot 1$ & $\mathrm{~N}$ \\
\hline 49 & 79 & 38.8 & 1.48 & 17.8 & $\mathbf{N}$ \\
\hline 52 & 70 & 63.8 & 1.55 & $26 \cdot 7$ & $\mathbf{Y}$ \\
\hline 54 & 74 & 50.0 & 1.52 & 21.5 & $\mathbf{N}$ \\
\hline 57 & 76 & 53.0 & 1.57 & 21.5 & $\mathrm{Y}$ \\
\hline 58 & 65 & $66 \cdot 9$ & 1.62 & $25 \cdot 4$ & $\mathrm{~N}$ \\
\hline 68 & 70 & $51 \cdot 0$ & 1.48 & $23 \cdot 2$ & Y \\
\hline 76 & 75 & $69 \cdot 0$ & 1.59 & 27.5 & $\mathrm{~N}$ \\
\hline 77 & 74 & 67.0 & 1.63 & $25 \cdot 2$ & $\mathrm{Y}$ \\
\hline 81 & 69 & $70 \cdot 0$ & 1.51 & $30 \cdot 7$ & $\mathrm{~N}$ \\
\hline 82 & 65 & 68.0 & 1.66 & $24 \cdot 8$ & $\mathbf{N}$ \\
\hline 84 & 65 & 52.5 & 1.51 & $23-2$ & $\mathbf{N}$ \\
\hline 85 & 69 & 66.0 & 1.52 & $28 \cdot 6$ & $\mathbf{N}$ \\
\hline 88 & 74 & 70.0 & 1.67 & $25 \cdot 1$ & $\mathbf{N}$ \\
\hline 89 & 69 & 58.5 & 1.51 & 25.7 & $\mathrm{~N}$ \\
\hline Mean & 70 & 63.0 & 1.57 & $25 \cdot 5$ & \\
\hline SD & 4 & 10.9 & 0.06 & 3.6 & \\
\hline
\end{tabular}

BMI, body mass index; $\mathrm{Y}$, yes; $\mathrm{N}$, no.

* Subjects who did not participate in the complete study were, by definition, not included in the measurements of total body water and underwater weighing.

obtained was converted to an estimate of body fatness ( $\mathrm{BF} \%$; percentage of body weight) using Siri's (1961) equation:

$$
\mathrm{BF} \%=(4 \cdot 95 / \text { density })-4 \cdot 50 .
$$

Fatness from body mass index (BMI)

BMI was calculated for all subjects and used in the appropriate predictive equation from Deurenberg et al. (1991) in order to estimate $\mathrm{BF} \%$.

$$
\mathrm{BF} \%=(1.2 \times \mathrm{BMI})-(10.8 \times \operatorname{sex})+(0.23 \times \text { age })-5.4,
$$

where sex is entered as male 1 , female 0 . 
Bio-electrical impedance $(B I A)$

Whole-body BIA was measured in all subjects at $800 \mu \mathrm{A}$ and $50 \mathrm{kHZ}$ using an EZ 1500 Body Composition Analyser (Cranlea and Co., Birmingham, West Midlands). The instrument employed the conventional tetrapolar method with electrodes attached to hand and foot. BF\% was estimated from the BIA measurement in two ways: (1) using the manufacturer's equation 'built in' to the instrument software; (2) using the appropriate equation derived from a healthy elderly population described by Deurenberg et al. (1990):

$$
\begin{gathered}
\text { FFM }(\mathrm{kg})=\left(0.671 \times 10^{4} \times \mathrm{H}^{2} / \mathrm{R}\right)+(3.15 \times \mathrm{S})+(3 \cdot 9) \\
\left(r^{2} 0.88 ; \text { standard error of estimate } 3.1 \mathrm{~kg}\right),
\end{gathered}
$$

where $H$ is height $(\mathrm{m}), \mathrm{R}$ is resistance (ohms), $\mathrm{S}$ is sex (entered as females 0 ; males 1). FM was calculated as (body weight - FFM), and expressed as a percentage of body weight.

\section{Densitometry}

Body density (BD) was measured in thirty-five of the sixty subjects by underwater weighing, as previously described, and residual lung volume was determined by $\mathrm{N}_{2}$ wash-out as previously described (Durnin \& Womersley, 1974).

Measurements of body density in men were converted to BF \% estimates using Siri's (1961) equation. In the women, BD was converted to BF \% using both the Siri equation and a modification of it suggested by Deurenberg et al. (1989). Deurenberg et al. (1989) demonstrated that FFM density in elderly women is lower than $1.100 \mathrm{~kg} / \mathrm{m}^{3}$ and proposed the following modification to Siri's equation in order to correct for the error observed:

$$
\text { Women age } 70 \text { years: } B F \%=(512 \cdot 1 / \text { density })-469 \cdot 0 \text {. }
$$

This equation makes the assumption that the density of FFM is $1.0919 \mathrm{~kg} / \mathrm{m}^{3}$ rather than $1 \cdot 100 \mathrm{~kg} / \mathrm{m}^{3}$ (Siri, 1961).

\section{Estimation of $B F \%$ from $T B W$}

TBW was estimated as ${ }^{2} \mathrm{H}^{2} \mathrm{HO}$ dilution space/1.04 (Schoeller et al. 1980). After providing a urine specimen for determination of background ${ }^{2} \mathrm{H}$ enrichment in body water, ${ }^{2} \mathrm{H}^{2} \mathrm{HO}$ space was measured from the 5-7 h post dose 'plateau' enrichment in urine following oral administration of a weighed dose of approximately $0.12 \mathrm{~g}{ }^{2} \mathrm{H}^{2} \mathrm{HO} / \mathrm{kg}$ body-weight. Background and 'plateau' ${ }^{2} \mathbf{H}$ enrichments were measured using an Aqua Sira isotope ratio mass spectrometer (Bureau for Stable Isotope Analysis, Brentford, Middlesex). TBW was calculated following correction to measured dilution space of ${ }^{2} \mathrm{H}^{2} \mathrm{HO}$ for density of water at $37^{\circ}$. Calculation of $\mathrm{BF} \%$ from TBW was made by assuming that the water content of FFM is $730 \mathrm{~g} / \mathrm{kg}$.

As indicated above, measurements of TBW, and estimates of BF \% derived from them, were available only for those subjects for whom body density was measured $(n 35)$, since TBW was only determined in those subjects who could undertake the underwater weighing procedure.

\section{Statistical analyses}

Differences between the subjects recruited to the present study and appropriate reference data (for age, weight, FM and FFM from SFT) were tested for statistical significance by $t$ test. Relationships between BF \% estimates produced from each of the methods were examined by correlation. Since correlation is an index of association rather than agreement between methods, methodological differences were analysed on the basis of individual 
Table 3. Estimates of percentage body fat $(B F \%)$ in male subjects by six methods*

\begin{tabular}{|c|c|c|c|c|c|c|}
\hline $\begin{array}{c}\text { Subject } \\
\text { no. }\end{array}$ & Densitometry $\dagger$ & BMI & $\begin{array}{c}\text { BIA§ } \\
\text { (manufacturer's } \\
\text { equation) }\end{array}$ & $\begin{array}{c}\text { BIA } \| \\
\text { (Deurenberg } \\
\text { et al. } \\
\text { equation) }\end{array}$ & SFT & TBW+t \\
\hline 02 & $20 \cdot 1$ & $30 \cdot 7$ & 25.5 & $36 \cdot 6$ & $32 \cdot 2$ & $19 \cdot 1$ \\
\hline 03 & $22 \cdot 1$ & 31.9 & $23 \cdot 1$ & $34 \cdot 1$ & $30 \cdot 0$ & $30 \cdot 2$ \\
\hline 04 & $23 \cdot 2$ & $28 \cdot 9$ & $25 \cdot 7$ & $34 \cdot 6$ & 26.6 & 27.0 \\
\hline 08 & $31 \cdot 0$ & 33.9 & $32 \cdot 8$ & $42 \cdot 1$ & $29 \cdot 6$ & $29 \cdot 4$ \\
\hline 09 & $30 \cdot 6$ & $37 \cdot 5$ & $32 \cdot 6$ & $41 \cdot 8$ & $32 \cdot 3$ & $33 \cdot 6$ \\
\hline 20 & $16 \cdot 3$ & $25 \cdot 6$ & $17 \cdot 4$ & $27 \cdot 0$ & $18 \cdot 1$ & $18 \cdot 0$ \\
\hline 22 & 21.9 & $28 \cdot 3$ & $10 \cdot 7$ & $28 \cdot 7$ & $23 \cdot 2$ & $22 \cdot 0$ \\
\hline 33 & $28 \cdot 0$ & $28 \cdot 5$ & $19 \cdot 0$ & 30.0 & $27 \cdot 7$ & $27 \cdot 0$ \\
\hline 37 & $23 \cdot 7$ & $24 \cdot 3$ & $24 \cdot 7$ & $34 \cdot 4$ & $28 \cdot 1$ & $27 \cdot 9$ \\
\hline 38 & $23 \cdot 6$ & $27 \cdot 3$ & $29 \cdot 5$ & $39 \cdot 3$ & $29 \cdot 6$ & $30 \cdot 0$ \\
\hline 39 & $26 \cdot 5$ & $32 \cdot 7$ & $33 \cdot 0$ & $42 \cdot 0$ & $22 \cdot 1$ & $24 \cdot 2$ \\
\hline 46 & $13 \cdot 8$ & $29 \cdot 6$ & $18 \cdot 2$ & $28 \cdot 7$ & $21 \cdot 2$ & $18 \cdot 3$ \\
\hline 51 & $15 \cdot 1$ & 26.6 & $13 \cdot \overline{3}$ & $22 \cdot 8$ & $19 \cdot 3$ & $18 \cdot 3$ \\
\hline 53 & $25 \cdot 2$ & $27 \cdot 1$ & 167 & $27 \cdot 3$ & $29 \cdot 4$ & $22 \cdot 8$ \\
\hline 67 & $28 \cdot 1$ & 32.9 & $34 \cdot 4$ & $42 \cdot 5$ & $29 \cdot 5$ & $32 \cdot 5$ \\
\hline 70 & 27.0 & $28 \cdot 1$ & $31 \cdot 6$ & $39 \cdot 2$ & $29 \cdot 1$ & $25 \cdot 1$ \\
\hline 75 & $24 \cdot 2$ & $26 \cdot 5$ & $20 \cdot 6$ & 31.0 & $23 \cdot 3$ & $19 \cdot 2$ \\
\hline 79 & 26.9 & 33.8 & $37 \cdot 1$ & 45.5 & $23 \cdot 8$ & $19 \cdot 8$ \\
\hline 87 & $26-1$ & $31 \cdot 4$ & $26 \cdot 1$ & $37 \cdot 3$ & $28 \cdot 1$ & 30.0 \\
\hline 06 & - & $36 \cdot 6$ & $27 \cdot 4$ & $37 \cdot 2$ & $27 \cdot 4$ & - \\
\hline 35 & - & 31.6 & $32 \cdot 1$ & 41.0 & $29 \cdot 0$ & - \\
\hline 43 & - & 28.0 & $35 \cdot 2$ & $42 \cdot 5$ & $26-5$ & - \\
\hline 50 & - & $37 \cdot 3$ & $40 \cdot 8$ & $47 \cdot 2$ & $27 \cdot 0$ & -- \\
\hline 55 & - & 31.9 & $28 \cdot 1$ & $37 \cdot 1$ & $25 \cdot 5$ & - \\
\hline 69 & - & $34 \cdot 4$ & $20 \cdot 6$ & 27.9 & $20-9$ & - \\
\hline 88 & - & $31 \cdot 3$ & $31 \cdot 0$ & $40 \cdot 0$ & $26 \cdot 0$ & - \\
\hline 89 & - & 28.0 & $28 \cdot 4$ & $38 \cdot 1$ & $27 \cdot 8$ & - \\
\hline Mean & 23.9 & 30.5 & $26 \cdot 5$ & $36 \cdot 1$ & $26 \cdot 4$ & $25 \cdot 0$ \\
\hline SD & $4 \cdot 8$ & $3 \cdot 6$ & $7 \cdot 6$ & 6.4 & $3 \cdot 8$ & $5 \cdot 2$ \\
\hline
\end{tabular}

BMI, body mass index, BIA, bioelectrical impedance; SFT, skinfold thickness; TBW, total body water.

* For details of subjects and procedures, see Table 1 and pp. 34-38.

$\uparrow$ Using the equation of Siri (1961).

$\ddagger$ Using the equation of Deurenberg et al. (1991).

$\S$ Using the manufacturer's 'built-in' equation.

$\|$ Using the equation of Deurenberg et al. (1990).

T Following the method of Durnin \& Womersley (1974).

††Assuming the water content of the fat-free mass is $730 \mathrm{~g} / \mathrm{kg}$.

differences in BF\% estimates between the various methods. These were expressed as the mean of the individual differences between methods in BF\% units ('bias') and the "limits of agreement' between methods (bias $\pm t \times$ SD of the differences) following the method of Bland \& Altman (1986). The appropriate value of $t$ was taken from statistical tables.

\section{RESULTS}

Differences between $\mathrm{BF} \%$ estimates using different methods: males

Individual $\mathrm{BF} \%$ estimates for each of the six methods used in males are presented in Table 3. Data are presented for each individual in order to illustrate the degree of variability in $\mathrm{BF} \%$ estimates for the same individual. 
Table 4. Comparison of various body composition methods in male subjects* ${ }^{*}$

(Biasł for estimates of body fatness§ as a percentage of body weight, with $95 \%$ limits of agreement $(t \mathrm{SD}$ ) given in parentheses)

\begin{tabular}{|c|c|c|c|c|c|c|}
\hline Method & Densitometry & $\begin{array}{l}\text { Body mass } \\
\text { index }\end{array}$ & $\begin{array}{c}\text { BIA } \\
\text { (Manufacturer's } \\
\text { equation) }\end{array}$ & $\begin{array}{c}\text { BIA } \\
\text { (Deurenberg } \\
\text { et al. }(1990) \\
\text { equation) }\end{array}$ & $\begin{array}{l}\text { Skinfold } \\
\text { thickness }\end{array}$ & $\begin{array}{l}\text { Total } \\
\text { body } \\
\text { water }\end{array}$ \\
\hline Densitometry & - & - & - & - & - & - \\
\hline Body mass index & $-5.9(8.6)$ & - & - & $\ldots$ & - & - \\
\hline $\begin{array}{l}\text { BIA (Manufacturer's } \\
\text { equation) }\end{array}$ & $-1 \cdot 0(12 \cdot 0)$ & $4.9(12 \cdot 4)$ & - & - & - & - \\
\hline $\begin{array}{l}\text { BIA (Deurenberg et al. } \\
\text { (1990) equation) }\end{array}$ & $-11 \cdot 1(9 \cdot 5)$ & $-5 \cdot 2(9 \cdot 7)$ & $-10 \cdot 2(4 \cdot 5)$ & - & - & - \\
\hline Skinfold thickness & $-2 \cdot 6(8 \cdot 4)$ & $3 \cdot 3(8 \cdot 9)$ & $-1.6(14 \cdot 0)$ & $8.5(11.7)$ & - & - \\
\hline Total body water & $-1 \cdot 1(8 \cdot 4)$ & $4 \cdot 8(10 \cdot 1)$ & $-0 \cdot 1(14 \cdot 1)$ & $10.0(12.0)$ & $1.5(7 \cdot 8)$ & - \\
\hline
\end{tabular}

BIA, bioelectrical impedance.

* For details of subjects and procedures, see Table 1 and pp. 34-38.

$\uparrow$ Comparisons between densitometry and total body water and the other methods are based on nineteen subjects; all other comparisons are based on twenty-seven subjects.

¥ The method at the top of the table minus the alternative method given at the left hand side provides the bias.

$\S$ Values for bias of fat-free mass (as a percentage of body weight) are equal and opposite to those given for percentage fat.

Methods tended to be highly correlated with each other and all of the indirect methods were highly correlated with body density $(n 19)$ : BMI $(r 0.55 ; P<0.05)$; BIA, manufacturer's equation $(r 0.67 ; p<0.01)$; BIA, Deurenberg et al. (1990) equation $(r 0.72$; $P<0.01)$; SFT $(r 0.62 ; P<0.01)$; TBW $(r 0.69 ; P<0.01)$. As indicated above, correlation is an index of association rather than agreement. The degree of agreement between methods was determined by the Bland \& Altman (1986) analysis which concentrates on individual differences; these results are presented below.

\section{Comparison between methods and densitometry: males}

The results of the Bland \& Altman (1986) analysis are given in Table 4. Table 4 confirms that the $95 \%$ limits of agreement between all methods were wide. Some distinct biases are apparent. In particular, for the consideration of methods in relation to densitometry ( $n$ 19) it is clear from Tables 3 and 4 that the BMI method and BIA using the equation of Deurenberg et al. (1990) tend to overestimate $\mathrm{BF} \%$ relative to densitometry (large negative bias when $\mathrm{BF} \%$ estimate is subtracted from $\mathrm{BF} \%$ by densitometry; Table 4). Agreement between BIA (manufacturer's equation), SFT, and TBW and densitometry was somewhat better as indicated by the smaller biases, but limits of agreement were wide, particularly for BIA (Table 4).

\section{Comparison between methods: males}

Table 4 confirms that the greatest bias exists for comparisons of BF \% from BIA using the equation of Deurenberg et al. (1990) which consistently overestimated BF \% relative to other methods. The next highest estimates were obtained by BMI. Bias between BIA (manufacturer's equation), SFT and TBW was less marked, but again limits of agreement were wide. 
Table 5. Estimates of percentage body fat $(B F \%)$ in female subjects by seven methods*

\begin{tabular}{|c|c|c|c|c|c|c|c|}
\hline $\begin{array}{c}\text { Subject } \\
\text { no. }\end{array}$ & $\begin{array}{c}\text { Densitometry } \dagger \\
\text { (Siri } \\
\text { equation) }\end{array}$ & $\begin{array}{c}\text { Densitometry } \ddagger \\
\text { (Deurenberg } \\
\text { et al. } \\
\text { equation) }\end{array}$ & BMI§ & $\begin{array}{c}\text { BIA } \| \\
\text { (Manufacturer's } \\
\text { equation) }\end{array}$ & $\begin{array}{c}\text { BIA } \\
\text { (Deurenberg } \\
\text { et al. } \\
\text { equation) }\end{array}$ & SFT $\dagger^{\dagger}$ & TBW \\
\hline 01 & 43.6 & $41 \cdot 6$ & $45 \cdot 3$ & 47.2 & $42 \cdot 5$ & 40.6 & 42.0 \\
\hline 07 & $45 \cdot 3$ & 43.6 & $42 \cdot 2$ & 38.7 & 49.6 & 37.4 & 42.6 \\
\hline 12 & 44.7 & $42 \cdot 6$ & 39.6 & $41 \cdot 1$ & $52 \cdot 3$ & 34.8 & $46 \cdot 5$ \\
\hline 15 & $36 \cdot 7$ & 34.5 & 46.7 & $45 \cdot 1$ & 55.3 & 38.5 & 38.4 \\
\hline 18 & 42.2 & $40 \cdot 0$ & $39 \cdot 2$ & 40.8 & $52 \cdot 1$ & $36 \cdot 7$ & $41 \cdot 9$ \\
\hline 19 & 37.9 & $35 \cdot 5$ & 40.7 & $34 \cdot 1$ & 47.0 & 39.5 & 37.4 \\
\hline 21 & $24 \cdot 4$ & 22.0 & 32.5 & 22.6 & $39 \cdot 2$ & $25 \cdot 9$ & $26 \cdot 1$ \\
\hline 26 & 52.9 & $52 \cdot 0$ & 39.0 & 44.0 & 54.0 & $35 \cdot 2$ & 43.7 \\
\hline 40 & 39.2 & 37.0 & 37.8 & $34 \cdot 1$ & $46 \cdot 9$ & $34 \cdot 4$ & 37.9 \\
\hline 42 & 26.6 & $24 \cdot 4$ & 37.4 & $23 \cdot 4$ & $37 \cdot 9$ & $25 \cdot 1$ & 27.0 \\
\hline 44 & $35 \cdot 9$ & 33.6 & 37.9 & $36 \cdot 6$ & $48 \cdot 4$ & $36 \cdot 9$ & $35 \cdot 1$ \\
\hline 47 & $23 \cdot 6$ & $21 \cdot 0$ & $42 \cdot 2$ & $41 \cdot 3$ & $52 \cdot 2$ & $37 \cdot 1$ & 39.5 \\
\hline 52 & $50 \cdot 7$ & 48.8 & 42.7 & 48.7 & $57 \cdot 1$ & 37.7 & $53 \cdot 0$ \\
\hline 57 & 31.5 & $29 \cdot 2$ & 37.9 & 34.7 & 46.7 & 32.9 & $32 \cdot 3$ \\
\hline 68 & 42.8 & $41 \cdot 1$ & 38.5 & 40.9 & 51.6 & $35 \cdot 7$ & 41.0 \\
\hline 77 & 45.9 & $44 \cdot 1$ & 41.9 & $47 \cdot 1$ & 49.5 & 38.0 & 39.5 \\
\hline 10 & - & - & 38.5 & $34 \cdot 6$ & $46 \cdot 3$ & $32 \cdot 5$ & - \\
\hline 23 & - & - & $54 \cdot 1$ & $42 \cdot 9$ & 54.0 & $44 \cdot 6$ & - \\
\hline 27 & - & - & $46 \cdot 1$ & $42 \cdot 4$ & 53.8 & 40.0 & - \\
\hline 31 & - & - & 41.8 & $48 \cdot 1$ & 57.4 & $38 \cdot 2$ & - \\
\hline 32 & - & - & 40.1 & $36 \cdot 5$ & 48.5 & $36 \cdot 6$ & - \\
\hline 45 & - & - & $45 \cdot 9$ & 44.5 & 54.6 & $36 \cdot 3$ & - \\
\hline 48 & - & - & $43 \cdot 3$ & 44.5 & $54 \cdot 2$ & $35 \cdot 1$ & - \\
\hline 49 & - & - & $34 \cdot 1$ & 22.7 & 36.0 & $24 \cdot 1$ & - \\
\hline 54 & - & - & 37.4 & $26 \cdot 6$ & 39.8 & $32 \cdot 3$ & - \\
\hline 58 & - & -. & 40.0 & 44.5 & 54.4 & 37.9 & - \\
\hline 76 & - & - & 44.9 & 39.8 & 50.6 & $35 \cdot 8$ & - \\
\hline 81 & - & - & $47 \cdot 3$ & $46 \cdot 6$ & $56 \cdot 4$ & 41.8 & - \\
\hline 82 & - & - & $39 \cdot 3$ & $43 \cdot 1$ & $53 \cdot 4$ & $39 \cdot 9$ & - \\
\hline 84 & - & - & 37.4 & $29 \cdot 3$ & 42.7 & 37.7 & - \\
\hline 85 & - & - & 44.5 & $44 \cdot 2$ & $55 \cdot 0$ & $35 \cdot 0$ & - \\
\hline 88 & - & - & 41.7 & $36 \cdot 3$ & 53.7 & $37 \cdot 1$ & - \\
\hline 89 & - & - & $42 \cdot 0$ & $35 \cdot 3$ & $46 \cdot 9$ & 38.7 & - \\
\hline Mean & $39 \cdot 0$ & 36.9 & 41.2 & 38.9 & $49 \cdot 7$ & $36 \cdot 1$ & 38.9 \\
\hline SD & 8.8 & $9 \cdot 2$ & $4 \cdot 2$ & $7 \cdot 4$ & $5 \cdot 8$ & $4 \cdot 4$ & 6.9 \\
\hline
\end{tabular}

BMI, body mass index; BIA, bioelectrical impedance; SFT, skinfold thickness; TBW, total body water.

* For details of subjects and procedures, see Table 2 and pp. 34-38.

$\uparrow$ Using the equation of Siri (1961).

\$ Using the equation of Deurenberg et al. (1989).

$\S$ Using the equation of Deurenberg et al. (1991).

II Using the manufacturer's 'built in' equation.

If Using the equation of Deurenberg et al. (1990).

$\dagger+$ Following the method of Durnin \& Womersley (1974).

$¥$ Assuming the water content of the fat-free mass is $730 \mathrm{~g} / \mathrm{kg}$.

Differences between $B F^{\%} \%$ estimates using different methods: females

Individual estimates of BF\% for each of the seven methods are presented in Table 5. Data are again presented for each individual in order to illustrate the degree of variability in $\mathrm{BF} \%$ estimates from the various methods.

As in the males, $\mathrm{BF} \%$ estimates from the various methods tended to be highly correlated with each other and with $\mathrm{BF} \%$ by densitometry. For example, correlation coefficients for 
Table 6. Comparison of various body composition methods in female subjects ${ }^{*} \dagger$

(Biasł for estimates of body fatness§ as a percentage of body weight, with $95 \%$ limits of agreement $(t \mathrm{SD})$ given in parentheses)

\begin{tabular}{|c|c|c|c|c|c|c|}
\hline Method & $\begin{array}{l}\text { Densitometry } \\
\text { (Deurenberg } \\
\text { et al. }(1989) \\
\text { equation) }\end{array}$ & $\begin{array}{l}\text { Body mass } \\
\text { index }\end{array}$ & $\begin{array}{c}\text { BIA } \\
\text { (Manufacturer's } \\
\text { equation) }\end{array}$ & $\begin{array}{c}\text { BIA } \\
\text { (Deurenberg } \\
\text { et al. }(1990) \\
\text { equation) }\end{array}$ & $\begin{array}{l}\text { Skinfold } \\
\text { thickness }\end{array}$ & $\begin{array}{l}\text { Total } \\
\text { body } \\
\text { water }\end{array}$ \\
\hline $\begin{array}{l}\text { Densitometry } \\
\text { (Deurenberg et al. } \\
\text { (1989) equation }\end{array}$ & - & - & - & - & - & - \\
\hline Body mass index & $-3 \cdot 2(18 \cdot 1)$ & - & - & - & - & - \\
\hline $\begin{array}{l}\text { BIA (manufacturer's } \\
\text { equation) }\end{array}$ & $-1.8(14.0)$ & $2 \cdot 4(11 \cdot 2)$ & - & - & - & - \\
\hline $\begin{array}{l}\text { BIA (Deurenberg et al. } \\
\text { (1990) equation) }\end{array}$ & $-12 \cdot 0(16.0)$ & $-8.5(9 \cdot 4)$ & $-10 \cdot 8(7 \cdot 5)$ & - & 一 & - \\
\hline Skinfold thickness & $1.5(16.4)$ & $5 \cdot 1(6 \cdot 3)$ & $2.8(10.4)$ & $13.5(9 \cdot 0)$ & - & - \\
\hline Total body water & $-2.0(11.9)$ & $1 \cdot 2(12 \cdot 1)$ & $-0.1(8.7)$ & $10-0(8 \cdot 7)$ & $-3.5(10 \cdot 4)$ & - \\
\hline
\end{tabular}

BIA, bioelectrical impedance.

* For details of subjects and procedures, see Table 2 and pp. 34-38.

$\uparrow$ Comparison between densitometry and total body water and the other methods are based on sixteen subjects; all other comparisons are based on thirty-three subjects.

\$ The method at the top of the table minus the alternative method given on the left hand side provides the bias.

$\S$ Values for bias of fat-free mass (as a percentage of body weight) are equal and opposite to those given for percentage fat.

BF \% from densitometry (Deurenberg et al. (1990) equation; $n$ 16) and other methods were as follows: BMI ( $r 0.38$; not significant); BIA, manufacturer's equation $(r 0.71 ; P<0.01)$; BIA, equation of Deurenberg et al. (1990) $(r 0.58 ; P<0.05)$; SFT $(r 0.56 ; P<0.05)$; TBW $(r 0.80 ; P<0.01)$.

\section{Comparison of methods with densitometry: females}

The results of the Bland \& Altman (1986) analysis are given in Table 6. Comparisons with densitometry are provided using the modification to Siri's equation proposed by Deurenberg et al. (1989). Table 6 confirms that the $95 \%$ limits of agreement between methods are wide. As in the males, some distinct biases were apparent (Tables 5 and 6). Comparison of the various methods with densitometry $(n 16)$ showed that the BIA method employing the age-specific equation for elderly people proposed by Deurenberg et al. (1989) consistently overestimated body fatness relative to densitometry. The equation based on BMI developed by Deurenberg et al. (1991) systematically overestimated BF \% relative to densitometry, though not to the same extent as in the males (Table 4). Biases for BIA, SFT, TBW and densitometry were considerably smaller but the limits of agreement were fairly wide (less so for TBW than the other methods).

\section{Comparison between methods: females}

The estimates of BF\% from the age-specific equation based on BIA of Deurenberg $e t$ al. (1990) were systematically higher than all other methods (Table 6), with estimates of BF \% from BMI next highest (Tables 5 and 6). Biases between the other methods were less clear though BIA tended to produce slightly higher estimates than SFT, and SFT tended to produce slightly lower estimates than TBW (Tables 5 and 6). As in the males, however, limits of agreement between these three methods were wide. 
The estimates of BF\% from densitometry using the correction of Deurenberg et al. (1989) are of course lower than those from Siri's equation (Table 5) because of the reduction in the constant assumed for the density of FFM.

\section{DISCUSSION}

The approach taken in the present study was to provide a comparison of two-component methods of body composition assessment. Historically such studies have tended to identify a particular method (usually densitometry) as a reference and then compare other methods against the one so designated. In the absence of cadaver analysis such approaches can at best only provide a test of the relative validity rather than absolute validity of any particular method. Given the likely variability in the composition of the FFM of elderly subjects outlined above, and indeed in younger adults (Fuller et al. 1992), not only is absolute validity out of the question, but to consider validity relative to a reference method such as densitometry is to put too much faith in the basic assumptions of the twocomponent model. We have therefore refrained from making judgements of validity of individual methods by comparison with densitometry as a reference method, though the data presented could be used in such a manner (Tables 4 and 6).

Comparison of $\mathrm{BF} \%$ estimates between the various methods revealed that BIA using the appropriate age-specific regression equation (Deurenberg et al. 1990) and prediction of BF \% by BMI (Deurenberg et al. 1991) both tended to overestimate body fatness relative to the other methods for males and females (Tables 3 and 4 males; Tables 5 and 6 females). Svendsen et al. (1991) also found that the age-specific BIA equation of Deurenberg et al. (1990) tended to overestimate fatness in their group of healthy elderly subjects, but we know of no other attempt to cross-validate this particular equation, or to cross-validate the prediction of BF \% from BMI. Real differences between populations or samples may exist and this finding tends to support the case for a greater degree of cross-validation of predictive formulas, as suggested by several investigators (e.g. Deurenberg et al. 1990; Baumgartner et al. 1991). These difficulties are likely to be exacerbated when attempts are made to validate methodology based on healthy elderly subjects in elderly populations who are ill or disabled and this represents a major methodological problem.

Bias between the other methods was not particularly marked (Tables 4 and 6 ) in males or females, but the degree of disagreement in BF \% estimates at the individual level might be considered high. Methodological comparison are often made solely by correlation which tends to mask differences between individuals (Bland \& Altman, 1986). Recent studies of younger adults have revealed marked differences between methods at the individual level (McNeill et al. 1991; Fuller et al. 1992). An alternative view may be that the inter-individual differences outlined in Tables 3-6 are inevitable and need not give rise to undue concern. Siri (1961) considered that individual differences between 'true' and estimated BF \% of approximately $3.5 \mathrm{BF} \%$ between methods were inevitable (arising from error in the basic assumptions and biological variability). Furthermore, comparison of BIA- (manufacturer's equation), TBW- and SFT- (Tables 3-6) derived estimates of BF\% perhaps illustrates a degree of disagreement between methods which is not surprising in the light of Siri's comment and may be of little concern. The absence of great bias between these three methods illustrates the apparently limited potential for large systematic differences between the three 'bedside' methods.

The degree of inter-individual variability in composition of the FFM, discussed above, means that differences between methods in elderly subjects might be expected to be greater than in younger adult groups. The present study provides some support for this hypothesis. Fuller et al. (1992) for example reported a bias for comparison of SFT and density of -0.66 
(2SD 5.00) BF\% and 2.63 (2SD 7.87) BF\% for comparison of BIA and density in twentyeight healthy adults (males and females, age range 18-59 years). McNeill et al. (1991) reported slightly wider limits of agreement between SFT-density and BIA-density in a smaller ( $n$ 14) sample of younger adult women: comparison of BF\% by density-SFT (bias $-0 \cdot 3,2 \mathrm{SD} 9 \cdot 8$ ); comparison of BF \% by density-BIA (bias $1 \cdot 7,2 \mathrm{SD} 8 \cdot 6$ ). In the present study, analogous (bias $\pm t \times \mathrm{SD}$ ) values for the comparison of SFT and density in men (Table 4) were $-2.6(8.4) \mathrm{BF} \%$ in men, $1.5(16.4) \mathrm{BF} \%$ in women. For comparison of BIA and density in men (Table 4) bias was $-1.0(12.0) \mathrm{BF} \%$ and $-1.8(14.0) \mathrm{BF} \%$ in women (Table 6). In both cases limits of agreement for men and women are somewhat greater than those reported by Fuller et al. (1992) but only marginally greater than those reported by McNeill et al. (1991).

Methods of body composition assessment which are technically simple and can therefore be used in epidemiological and routine clinical settings (SFT, BMI, BIA, and possibly TBW) are of great importance in consideration of nutritional status of the elderly, and further research on the validity and practical utility of the various methods is indicated. A multicomponent approach is likely to be of great use in body composition assessment of the elderly (Baumgartner et al. 1991; Svendsen et al. 1991; Virgili et al. 1992), but crossvalidation in different populations must be demonstrated. It is also likely that, with some modifications, the existing 'bedside' two-component methods will remain and the characterization of differences between these methods is of obvious relevance. We conclude that in healthy elderly subjects large systematic differences between D, BIA (at least using the instrumentation software employed here), TBW and SFT are not present. The choice of which method to use in particular circumstances might therefore make little difference in practical terms, particularly if data are to be considered on a group basis.

We thank the volunteers for their co-operation, Dr W. Ferrell who provided medical cover, and Nigel Fuller for his comments on the manuscript. Financial support for the study was provided by the Wellcome Trust (Vacation Scholarship to L. Murray), and the University of Glasgow Medical Research Funds (funding for Electronic Chair Scales).

\section{REFERENCES}

Baumgartner, R. N., Heymsfield, S. B., Lichtman, S., Wang, J. \& Pierson, R. N. (1991). Body composition in elderly people; effect of criterion estimates on predictive equations. American Journal of Clinical Nutrition $\mathbf{5 3}$, 1345-1353.

Bland, J. M. \& Altman, D. G. (1986). Statistical methods for assessing agreement between two methods of clinical measurement. Lancet i, 307-310.

Burr, M. L. \& Phillips, K. M. (1984). Anthropometric norms in the elderly. British Journal of Nutrition 51, 165-169.

Cohn, S. H., Vartsky, D. \& Yasamura, S. (1980). Compartmental body composition based on total body nitrogen, potassium and calcium. American Journal of Physiology 239, E524-E530.

Deurenberg, P., Van der Kooy, K., Evers, P. \& Hulshoff, T. (1990). Assessment of body composition by bioelectrical impedance in a population aged $>60$ years. American Journal of Clinical Nutrition 51, 3-6.

Deurenberg, P., Westrate, J. A. \& Seidell, J. C. (1991). Body mass index as a measure of body fatness: age and sex specific prediction formulas. British Journal of Nutrition 65, 105-114.

Deurenberg, P., Westrate, J. A. \& Van der Kooy, K. (1989). Is an adaptation of Siri's formula for the calculation of body fat percentage from body density in the elderly necessary? European Journal of Clinical Nutrition $\mathbf{4 3}$, $559-568$.

Durnin, J. V. G. A. (1983) Body composition and energy expenditure in elderly people. Bibliotheca Nutritia Dieta $3,16-30$.

Durnin, J. G. A. \& Womersley, J. (1974). Body fat assessed from total body density and its estimation from skinfold thickness: measurements on 481 men and women aged from 16 to 72 years. British Journal of Nutrition 32, 77-97.

Forbes, G. B. (editor) (1987). Human Body Composition: Growth, Ageing, Nutrition and Activity. New York: Springer Verlag. 
Friedl, K. E., Deluca, J. P., Marchitelli, L. J. \& Vogel, J. A. (1992). Reliability of body fat estimations from a four compartment model by using density, body water and bone mineral measurements. American Journal of Clinical Nutrition 55, 64-70.

Fuller, N. J., Jebb, S. A., Laskey, M. A., Coward, W. A. \& Elia, M. (1972). A four component model for the assessment of body composition in humans. Clinical Science 82, 687-693.

Heymsfield, S. B., Wang, J., Lichtman, S., Kamen, Y., Kehayias, J. \& Pierson, R. N. (1989). Body composition in elderly subjects: a critical appraisal of clinical methodology. American Journal of Clinical Nutrition 50 , $1167-1175$.

Kuczmarski, R. J. (1989). Need for body composition information in elderly subjects. American Journal of Clinical Nutrition 50, 1150-1157.

McNeill, G., Fowler, P. A., Maughan, R. J., McGaw, B. A., Fuller, M. F., Govzdanovic, D. \& Govzdanovic, S. (1991). Body fat in lean and overweight women estimated by six methods. British Journal of Nutrition 65, 95-103.

Mazess, R. B. (1982). On ageing bone loss. Clinical Orthopaedic Research 165, 239-252.

Reilly, J. J., Murray, L. A., Wilson, J. \& Durnin, J. V. G. A. (1993). Prediction of body density from skinfold thickness in elderly subjects: are the existing equations valid? Proceedings of the Nutrition Society 52, 346A.

Schoeller, D. A. (1989). Changes in total body water with age. American Journal of Clinical Nutrition 50, 1176-1181.

Schoeller, D. A., Van Santen, E., Peterson, D. W., Dietz, W., Jaspan, J. \& Klein, P. D. (1980). Total body water measurement in humans with ${ }^{18} \mathrm{O}$ and ${ }^{2} \mathrm{H}$ labelled water. American Journal of Clinical Nutrition 33, 2686-2693.

Siri, W. E. (1961). Body composition from fluid spaces and density: analysis of methods. In Techniques for Measuring Body Composition, pp. 223-244. [J. Brožek and A. Henschel, editors]. Washington DC: National Academy of Sciences.

Svendsen, O. L., Haarbo, J., Heitmann, B. L., Gotfredser, A. \& Christiansen, C. (1991). Measurement of body fat in elderly subjects by dual energy X-ray absorptiometry, bio-electrical impedance, and anthropometry. American Journal of Clinical Nutrition 53, 1117-1123.

Virgili, F., D'Amicis, A. \& Ferro-Luzzi, A. (1992). Body composition and body hydration in old age estimated by means of skinfold thickness and deuterium dilution. Annals of Human Biology 19, 57-66. 